\title{
Analysis of Genome Size of Sixteen Coffea arabica Cultivars Using Flow Cytometry
}

\begin{abstract}
Josue Ortega-Ortega, Francisco Arturo Ramírez-Ortega, Roberto Ruiz-Medrano, and Beatriz Xoconostle-Cázares ${ }^{1}$ Departamento de Biotecnología y Bioingeniería, Centro de Investigación y de Estudios Avanzados del Instituto Politécnico Nacional Av. Instituto Politécnico Nacional, 2508 San Pedro Zacatenco, 07360 CDMX, México
\end{abstract}

Additional index words. Coffea, genome size, DNA content, flow cytometry, genetic diversity

\begin{abstract}
Coffee is an important crop worldwide, grown on about 10 million hectares in tropical regions including Latin America, Africa, and Asia. The genus Coffea includes more than 100 species; most are diploid, except for $C$. arabica, which is allotetraploid and autogamous. The genetic diversity of commercial coffee is low, likely due to it being selfpollinating, in addition, the widespread propagation of few selected cultivars, such as Caturra, Bourbon, and Typica. One approach is the analysis of genome size in these cultivars as a proxy to study its genetic variability. In the present work, genome size of 16 cultivars was assessed through high-resolution flow cytometry (FCM). Nuclear DNA was analyzed using a modified procedure that uses propidium iodide (PI) and 4', $6^{\prime}$-diamino2-phenylindole dihydrochloride hydrate (DAPI) staining. The $C$. arabica cultivars investigated possessed a nuclear DNA content ranging from $2.56 \pm 0.016 \mathrm{pg}$ for Typica, to $3.16 \pm 0.033 \mathrm{pg}$ for ICATU, which had the largest genome size. All cultivars measured using both fluorochromes had greater estimates with DAPI than PI. The proportion of the genome composed of guanosine and cytosine (GC\%) among the cultivars evaluated in this study ranged from $37.03 \%$ to $39.22 \%$. There are few studies of genome size by FCM of distinct important $C$. arabica cultivars, e.g., hybrids and artificial crosses. Thus, this work could be valuable for coffee breeding programs. The data presented here are intended to expand the genomic understanding of $C$. arabica and could link nuclear DNA content with evolutionary relationships such as diversification, hybridization and polyploidy.
\end{abstract}

Coffee is an important commodity in terms of international trade (The Observatory of Economic Complexity, 2018) and is grown in Latin America, Africa, and Asia, covering a surface of 10 million ha (Mishra and Slater, 2012). Coffee cultivars belong to the genus Coffea (Rubiaceae family), which includes more than 100 mostly diploid species $(2 n=$ $2 x=22)$, except for C. arabica $(2 n=4 x=44)$, which is autogamous and allotetraploid (Noirot et al., 2003a). Most world coffee production comes from $C$. arabica, of which the most common cultivars are Caturra, Catuai, Bourbon, and Typica (International Coffee Organization, 2018). However, genetic diversity of $C$. arabica is considered low, due likely to genetic bottlenecks caused by propagation of few individuals from selected cultivars for commercial purposes (Cubry et al., 2008; Lashermes et al., 2011). Thus,

Received for publication 25 Jan. 2019. Accepted for publication 6 Mar. 2019.

The authors thank Victor Rosales for his technical assistance and members of the laboratory for helpful discussions. This work was supported by a $\mathrm{PhD}$ fellowship provided by CONACyT to JO-O and CONACyT grants $(105985,158801$, and FC-2015-2, 01234 to B.X.C. and 156162 to R.R.M.).

${ }^{1}$ Corresponding author. E-mail: bxoconos@ cinvestav.mx. besides its economic and agricultural relevance, Coffea species and C. arabica cultivars can shed light on the domestication and evolution of this genus through analysis of genome sequence and nuclear genome size, among other approaches (Barre et al., 1996; Herrera et al., 2002). Genome size is incongruent with the ploidy level and number of basic chromosome sets of an organism (Huang et al., 2013; Tatum et al., 2006). Nuclear DNA content ( $\mathrm{C}$ value) is an important trait revealing the correlation between genome size and phenotype. For a haploid genome, the abbreviations of $\mathrm{C}$-value are represented as $1 \mathrm{C}$ (Bennett and Leitch, 2005; Greilhuber and Doležel, 2009; Greilhuber et al., 2005a). More than $8500 \mathrm{C}$-values of plant species have been estimated to date (Bennett and Leitch, 2012). The DNA content in angiosperms varies widely, ranging from $1 \mathrm{C}=0.165 \mathrm{pg}$ in Arabidopsis thaliana to $1 \mathrm{C}=152.23 \mathrm{pg}$ in the species Paris japonica (Bennett et al., 2003; Dodsworth et al., 2015). Also, intraspecific variation in $\mathrm{C}$-values is at times remarkably divergent for the same species (Grover et al., 2008; Leong-Skornickova et al., 2007; Price 1988; Yan et al., 2016).

FCM has been used extensively for the determination of DNA content (Doležel et al., 1998). Previous reports using FCM have described intraspecific genome size variation in Coffea species (Cros et al., 1995; Noirot et al.,
2000, 2003b; Razafinarivo et al., 2012). Nevertheless, some of the observed $2 \mathrm{C}$ value differences result from the interaction of cytosolic compounds such as caffeine and chlorogenic acids with the dye, thus interfering with its accessibility to DNA (Greilhuber, 2005; Noirot et al., 2000, 2002, 2003b). Different methodologies have been proposed to reduce spurious variations (stoichiometric errors) and erroneous genome size estimations (Doležel and Bartos, 2005; Doležel et al., 2007; Noirot et al., 2005). Likewise, some variations in nuclear DNA content between species are possibly artifacts caused by the inability of the dye to access DNA, since the fluorescent stains PI and DAPI can yield significantly different values for the same sample (Noirot et al., 2002; 2003b). The studies on nuclear DNA content in C. arabica cultivars by FCM have been reported (Carvalho et al., 2011; Clarindo and Carvalho, 2009; Clarindo et al., 2012, 2013; Sanglard et al., 2017; Sattler et al., 2016), and therefore additional studies on more cultivars will be helpful for breeding programs, as well as, from a basic standpoint, for phylogenetic analysis of coffee cultivars.

Coffea cultivars bear an open-pollination strategy, thus generating heterozygous individuals and populations with genetic variability. The approach of characterizing these new cultivars with attractive traits for the consumer, as well as to test tolerance or resistance to biotic and abiotic stress, is important to assist genetic breeding programs and generate new individuals with new adaptations to climate change (Giles et al., 2019). Climate instability such as extreme temperature is a threat to Coffea production (Ramalho et al., 2014). Indeed, Coffea cultivars mitigate heat stress in greater $\mathrm{CO}_{2}$ concentrations (Martins et al., 2016, 2017; Rodrigues et al., 2016). The genetic divergence in Coffea is extensively described and quantitative trait loci associated with phenotypes were identified using multivariate procedures (Giles et al., 2018; Machado et al., 2017). Knowledge of base composition in woody plants may provide additional insight into the relationship between $\mathrm{GC} \%$ and climatic adaptability (Contreras and Shearer 2018).

In this study, a high-resolution flow cytometric estimation of genome size was obtained for 16 commercially important $C$. arabica cultivars, using a modified procedure with PI and DAPI staining, identifying significant differences in DNA content, and thus allowing the identification of diverse groups. Moreover, a protocol for purification of nuclei was used to avoid spurious variations and erroneous genome size estimations. The data presented here are intended to expand the genomic understanding of $C$. arabica and correlate nuclear DNA content as well as base composition with evolutionary relationships such as diversification, hybridization, and polyploidy.

\section{Materials and Methods}

\section{Plant material}

Leaves were collected from 16 healthy C. arabica cultivars in consideration of its 
commodity value, according to International Coffee Organization (2018) and the World Coffee Research (2018). Glycine max (soybean) and Coffea canephora leaves were used as standards with known genome content. Plants were grown in greenhouse at full irrigation and long-day photoperiod (16-/8-h) conditions.

\section{FCM analysis}

Nuclei isolation. This process was carried out essentially as described (Noirot et al., 2005). Basically, sections of young leaves $\left(2 \mathrm{~cm}^{2}\right)$ were macerated in a small plastic petri dish using a sharp razor blade in $400 \mu \mathrm{L}$ of nuclei extraction buffer (CyStain ultraviolet Precise P; Partec, Görlitz, Germany); 2 mm dithiothreitol (Sigma-Aldrich, St. Louis, MO) was added to minimize interference of phenolic compounds with DNA staining (Doležel and Bartos, 2005). Samples were incubated for $2 \mathrm{~h}$ in the dark, after which the mixture was filtered through a $30-\mu \mathrm{m}$ nylon mesh disposable filter (CellTrics; Sysmex, Milton Keynes, UK) and transferred to a 2-mL microcentrifuge tube. To avoid artifactual variations and erroneous genome size estimations, the mixture was centrifuged at $200 \mathrm{~g}$ for $15 \mathrm{~min}$ and the supernatant discarded. Finally, nuclei were treated with $50 \mu \mathrm{g} / \mathrm{mL}$ RNase A (Sigma-Aldrich) and stained. Two different compounds were used for staining, PI $(50 \mu \mathrm{g} / \mathrm{mL})$ (excitation/emission wavelengths: 480-575/550-740 nm) (SigmaAldrich) as well as a nuclei staining buffer containing DAPI (excitation/emission wavelengths: 320-385/415-520) (Shapiro 2005) (CyStain ultraviolet Precise P; Partec). Both staining treatments were supplemented with 2 mM dithiothreitol, which also helps maintain the integrity of chromatin (Doležel and Bartos, 2005).

Experimental design. The experimental design was adopted following the recommendations of Clarindo et al. (2012) for nuclei extraction from multiple leaves, from two standards, soybean $(2 \mathrm{C}=2.30 \mathrm{pg}$ and $C$. canephora $(2 \mathrm{C}=1.29 \mathrm{pg})$ (values obtained in the present work). FCM parameters, such as gain and channel, were determined for each DNA content measurement, based on FCM assessments of standard and samples (control and target) as described by Clarindo et al. (2013). In addition, the test for the presence of inhibitors was carried out based on the reported by Huang et al. (2013) and Choudhury et al. (2014). Genome size was determined using a LSR Fortessa flow cytometer (Becton Dickinson, Franklin Lakes, NJ) PI fluorescence was excited with a 50-mW argon laser (Saphire; Coherent, Santa Clara, CA) at $488 \mathrm{~nm}$ using a 585-nm band-pass filter. DAPI fluorescence was excited through a $65-\mathrm{mW}$ argon laser (Genesis CX 355; Coherent) tuned to ultraviolet excitation at $355 \mathrm{~nm}$ using a 450 $\mathrm{nm}$ band-pass filter.

The data analysis was carried out with the Kaluza software (Beckman Coulter, Indianapolis, IN) and gated to selectively observe all nuclei of interest, which gather densely in a dot-plot map while eliminating results from unwanted particles. Three independent repetitions from multiple leaves, accounting for more than 5000 nuclei, were performed in each analysis. The average of $\mathrm{CV}$ values was used to evaluate the results, with which $\mathrm{CV}$ closer to $5 \%$ were considered as reliable. $\mathrm{Cv}$ is defined as $\mathrm{CV}=\mathrm{D} / \mathrm{M} \times 100 \%$; $\mathrm{D}$ is the standard deviation of the cell distribution and $\mathrm{M}$ is the average of cell distribution. (Huang et al., 2013). The genome size ratio of C. arabica cultivars was calculated by the equation: nuclear DNA content $=$ (mean position of sample peak) / (mean position of standard peak) - DNA content of the standard (Doležel and Greilhuber, 2010). The mean nuclear $2 \mathrm{C}$ value was determined for each sample in picograms (pg) by multiplying the mean ratio by the $2 \mathrm{C}$ value of the standard (Doležel and Greilhuber, 2010).

\section{Base composition}

The base pair (bp) composition of 16 cultivars was evaluated. \%bp was estimated according to the equation: adenine thymine percentage $(\mathrm{AT} \%)=\mathrm{AT} \%$ for internal standard [(mean fluorescence standard DAPI / mean fluorescence sample DAPI) / (mean fluorescence standard PI / mean fluorescence sample PI)] ( ${ }^{1 / \text { binding length }}$ ) (Contreras and Shearer, 2018; Godelle et al., 1993), where AT\% of primary standard is 63.6 and the binding length of DAPI is 3.5 (Meister and Barow, 2007). Values reported in Table 1 were calculated as $\mathrm{GC} \%=100-\mathrm{AT} \%$.

\section{Statistical analysis}

To assess for significant differences between $C$. arabica cultivars genome size values, Fisher's least significant difference (LSD) test was employed, LSD $_{0.05}=0.13356$ was calculated to determine the greater limit allowed between each treatment mean to consider whether they belong to the same population. Then, the real difference was calculated between the population average, relative to the $\mathrm{LSD}_{0.05}=0.13356$. A $t$ test was used to compare genome size values for 16 cultivars calculated using both DAPI and PI to determine whether differences were significant using these two fluorochromes. Sigma Plot 14.0 software (Systat Software, San Jose, CA) was used to perform the statistical analysis.

\section{Results}

Standardization of nuclear DNA content quantification. To carry out the quantification of DNA content of the $C$. arabica cultivars, the G0/G1 peak value of soybean (primary standard) was tuned to fluorescence channel 163. The genome size mean values were obtained in picograms $(2 \mathrm{C}=2.30 \pm 0.030$ pg) (Fig. 1). C. canephora also was used (secondary standard) (data shown in Supplemental Tables 1-3) to determine FCM parameters; the $\mathrm{G} 0 / \mathrm{G} 1$ peak was tuned to channel 92 and the genome size was calculated to $2 \mathrm{C}=1.29 \pm 0.051 \mathrm{pg}$ (Fig. 1). FCM parameters were determined for each DNA content measurement, based on FCM assessments of standards and samples.
FCM histograms of C. arabica cultivars. Mean fluorescence values from 16 C. arabica cultivars showed G0/G1 nuclei peaks in a fluorescence range from 181.7 to 216.91 with nuclei count between 3500 and 5000, four representative cytograms are shown in Fig. 1A-D. In terms of genome content, two groups were identified. In the first group are those with progenitors are the 'Bourbon' and 'Typica,' whereas the second group includes those that possess some genetic traits from another cultivar (artificial crosses) or species (hybrids), mainly $C$. canephora and also sometimes C. liberica as well as hybrids (Fig. 2) (World Coffee Research, 2018). The histograms of suspensions of isolated nuclei stained with PI exhibited $\mathrm{CV}$ values varying between $4.12 \%$ and $5.73 \%$, which suggests that the resolutions of the histograms were appropriate for genome size analysis (Table 1).

Assessment of genome size in $\mathrm{C}$. arabica cultivars. Considering the relative G0/G1 nuclei peak of PI fluorescence corresponding to the primary standard (soybean) and to the sample, the mean ratio of $2 \mathrm{C}$ values was calculated as a linear relationship between the ratio of $2 \mathrm{C}$ value peaks of the sample and standards. C. arabica cultivars possessed a nuclear DNA content ranging from $2.56 \pm$ 0.016 to $3.16 \pm 0.033 \mathrm{pg}$. 'Typica' had the smallest genome size, whereas ICATU had the largest genome size (Fig. 3). The nuclear DNA content values of 'Bourbon' $(2 \mathrm{C}=$ $2.86 \pm 0.010)$, 'Maragogype' $(2 \mathrm{C}=2.61 \pm$ $0.049 \mathrm{pg})$, 'Pluma Hidalgo' $(2 \mathrm{C}=2.66 \pm$ $0.007 \mathrm{pg})$, 'Villa Sarchi' $(2 \mathrm{C}=2.76 \pm 0.065$ $\mathrm{pg})$, and 'Caturra' $(2 \mathrm{C}=2.88 \pm 0.040 \mathrm{pg})$ ('Typica' genetic family) are congruent with the genealogy of the coffee cultivars analyzed in this study as shown in Fig. 4. The cultivars Catuai and Mundo Novo genome size values $(2 \mathrm{C}=2.88 \pm 0.053$ and $2.90 \pm$ $0.031 \mathrm{pg}$, respectively) were similar to the Brazilian cultivars Catuai Vermelho IAC 15 (UFV 2237 cova 148 EL7) as well as Mundo Novo IAC 376-4-32 (UFV 2150) Cova 39 (Bourbon Vermelho $\times$ Sumatra) reported by Clarindo and Carvalho (2009), Clarindo et al. (2013), and Fontes (2003). 'Garnica' (2C = $2.93 \pm 0.021 \mathrm{pg})$ and 'Garena' $(2 \mathrm{C}=3.03 \pm$ $0.035 \mathrm{pg}$ ) showed similar DNA content values, whereas 'Colombia' $(2 \mathrm{C}=3.05 \pm$ $0.022)$, 'IAPAR 59' $(2 \mathrm{C}=3.05 \pm 0.080 \mathrm{pg})$, 'Costa Rica' $(2 \mathrm{C}=3.12 \pm 0.125)$, and 'Oro Azteca' $(2 \mathrm{C}=3.15 \pm 0.021 \mathrm{pg})$ showed a greater DNA content value, possibly due to its hybrid nature (Fig. 4). The genome size values obtained with DAPI were always greater in all cultivars (Table 1). The fluorochromes comparison between DAPI and PI for all cultivars showed significant difference $(P<0.001)$ in $2 \mathrm{C}$ values (Table 1$)$. Genome size differences using both fluorochromes varied in a range of 0.18 to 0.52 (Table 1 ). The lowest difference in genome size using DAPI and PI was found in Costa Rica cultivar $(0.18)$, whereas the greatest difference was found in the Maragogype cultivar (0.52). The $\mathrm{AT} \%$ was determined in the cultivars evaluated in a range of $60.78 \%$ to $62.97 \%$. The GC $\%$ contents ranged from $37.03 \%$ to $39.22 \%$ 
Table 1. Genome size and bp composition of 16 C. arabica cultivars stained with PI and DAPI using soybean $(2 \mathrm{C}=2.30 \mathrm{pg})$ as the standard.

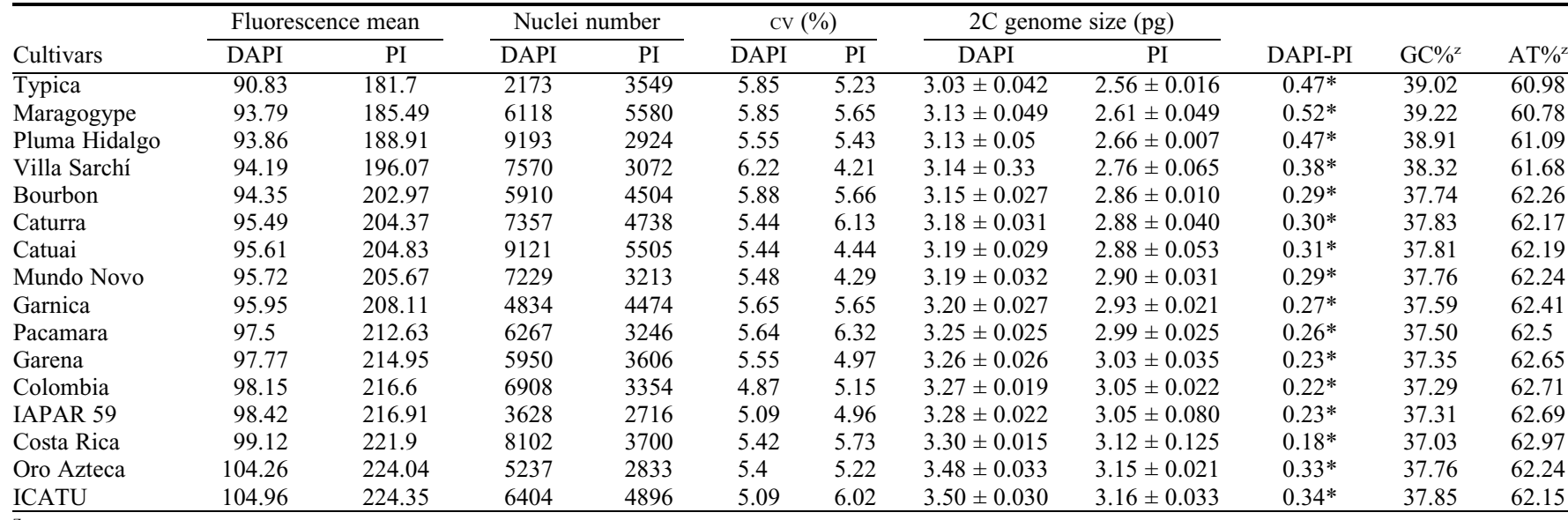

${ }^{\mathrm{z}} \mathrm{GC} \%=100-\{\mathrm{AT} \%$ for standard · [ mean fluorescence standard DAPI / mean fluorescence sample DAPI) / (mean fluorescence standard PI $/$ mean fluorescence sample PI)] (1/binding length) $\}$ (Contreras and Shearer, 2018) (Godelle et al., 1993), where AT\% of internal standard $=63.6$ and binding length of DAPI $=3.5$ (Meister and Barow 2007).

*Significant difference $(P<0.001)$ based on $t$ test comparing mean 2C genome size determined using DAPI with PI.

$\mathrm{bp}=$ base pair; PI = propidium iodide; DAPI $=4^{\prime}, 6^{\prime}$-diamino-2-phenylindole dihydrochloride hydrate.

A

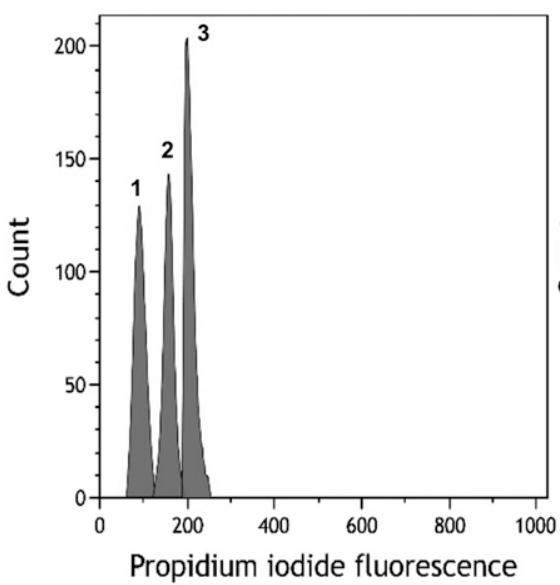

B

C

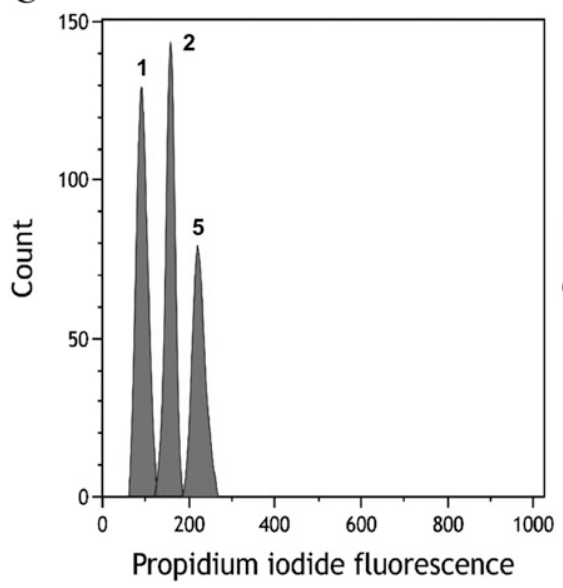

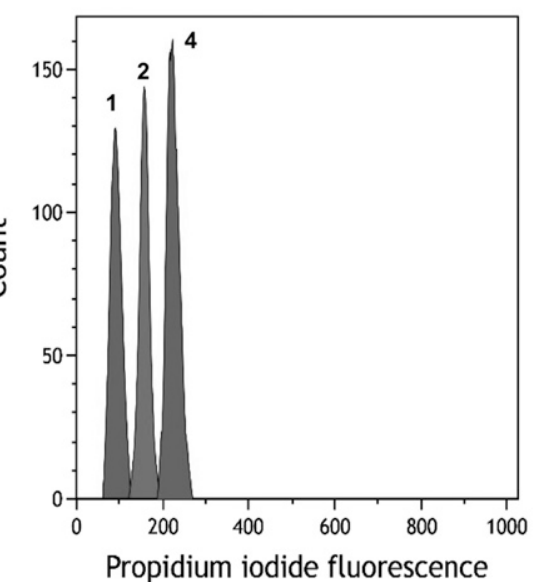

D

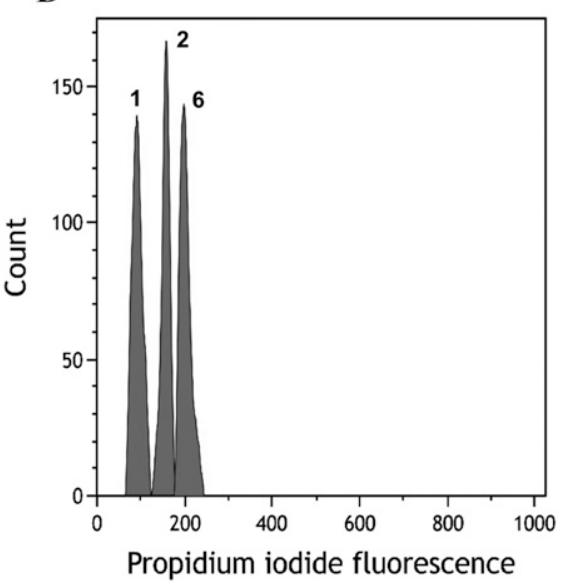

Fig. 1. Representative cytograms of fluorescence intensity by flow cytometry of G0/G1 nuclei from some C. arabica cultivars and standards. Representative cytograms showing $\mathrm{G} 0 / \mathrm{G} 1$ peaks with cvs ranging between $3.76 \%$ and $4.58 \%$, obtained from propidium iodide-stained nuclear suspensions prepared from leaves of comparison standards; 1) soybean (channel 163.6) $(2 \mathrm{C}=2.30 \mathrm{pg})$ and 2) C. canephora (channel 92.85) $(2 \mathrm{C}=1.29 \mathrm{pg})$. Four representative C. arabica cultivars are shown. (A) Catuai 3) channel fluorescence 204.83 ( $2 \mathrm{C}$ value $=2.88 \mathrm{pg}$ ); (B) ICATU 4) channel fluorescence 224.35 (2C value $=3.16 \mathrm{pg})(\mathbf{C})$ Oro Azteca 5$)$ channel fluorescence $224.04(2 \mathrm{C}$ value $=3.15 \mathrm{pg})$; and $(\mathbf{D})$ Typica 6) channel fluorescence $181.7(2 \mathrm{C}$ value $=2.56 \mathrm{pg})$.

(Table 1). Moreover, the genome size with PI was reproducible using two standards $(C$. canephora and soybean); a linear correlation between the fluorescence and the DNA content with an $R^{2}=0.98$ was found, and a similar slope in all evaluated $C$. arabica cultivars. This reproducible parameter allowed us to estimate that the nuclear DNA content in picograms is very similar, regardless of which standard was used to compare the DNA content (Fig. 5).

\section{Discussion}

In the present work, 16 C. arabica cultivars were selected for analysis, according to their global commodity value in different countries. C. arabica lineages analyzed in this study were classified into two groups that agree with previously reported phylogenies obtained through other methods (Anthony et al., 2002; Machado et al., 2017; Steiger et al., 2002). The first group corresponds to the 'Bourbon' and 'Typica' genetic family; the most important cultivars of this group are 'Pluma Hidalgo' and 'Maragogype', which are natural mutations of 'Typica'. 'Villa Sarchi' and 'Caturra' are natural mutations of 'Bourbon', besides hybrids such as 'Mundo Novo' ('Typica' $\times$ 'Bourbon') and 'Catuai' ('Mundo Novo' $\times$ 'Caturra'). These cultivars are associated with high cup quality but are susceptible to the major coffee diseases, such as coffee rust. Due to the presence of this disease, cultivars that show some degree of resistance have been introduced. The second group includes artificial crosses between different $C$. arabica cultivars, for example, 'Garnica' ('Mundo Novo' $\times$ 'Caturra') and their natural mutation 'Garena'. This also group includes hybrids, such as 'IAPAR 59' ('Villa Sarchi' $\times$ 'Timor Hybrid 832/2'), 'Colombia' ('Caturra' $\times$ 'Timor Hybrid 1343'), 'Costa Rica' ('Timor Hybrid 832/1' × 'Caturra'), 'Oro Azteca' ('Timor Hybrid 832/1' $\times$ 'Caturra'), and 


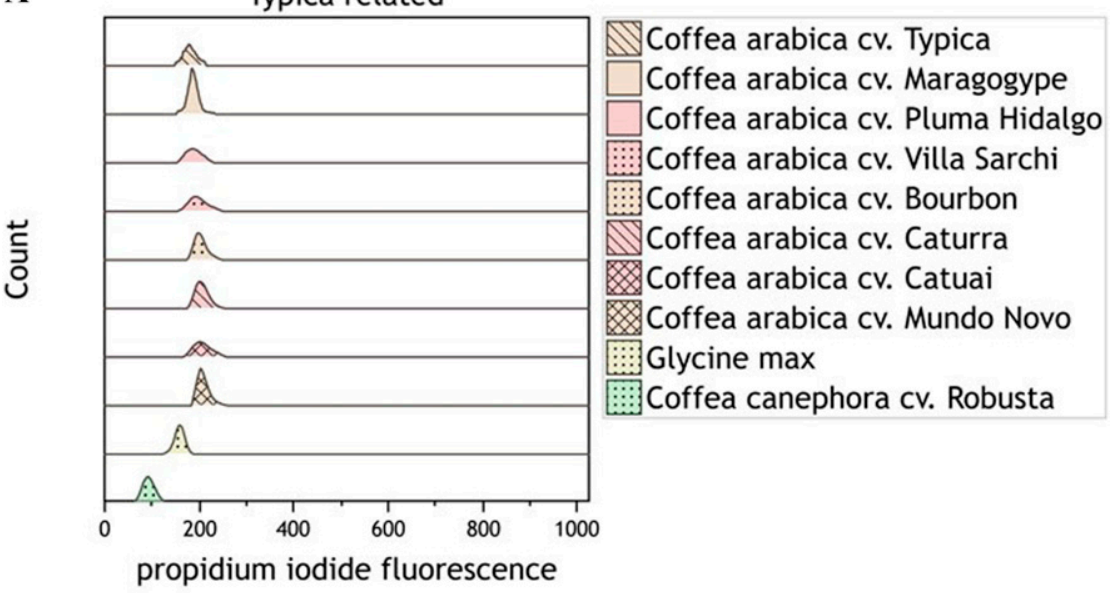

B

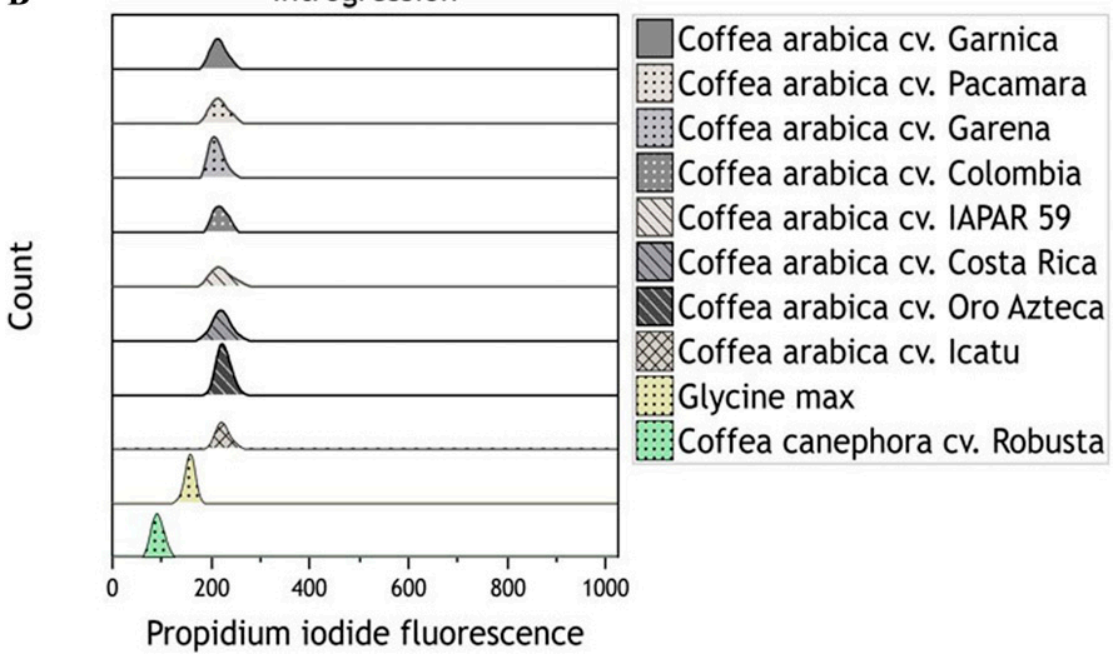

Fig. 2. Cytograms of relative DNA content of nuclei isolated from 16 C. arabica cultivars associated to propidium iodide fluorescence. (A) 'Typica'-related family. As controls, soybean and Coffea canephora var. Robusta also are shown. (B) Introgressed (artificial crosses and hybrids) cultivars. Controls similar to (A) were employed.

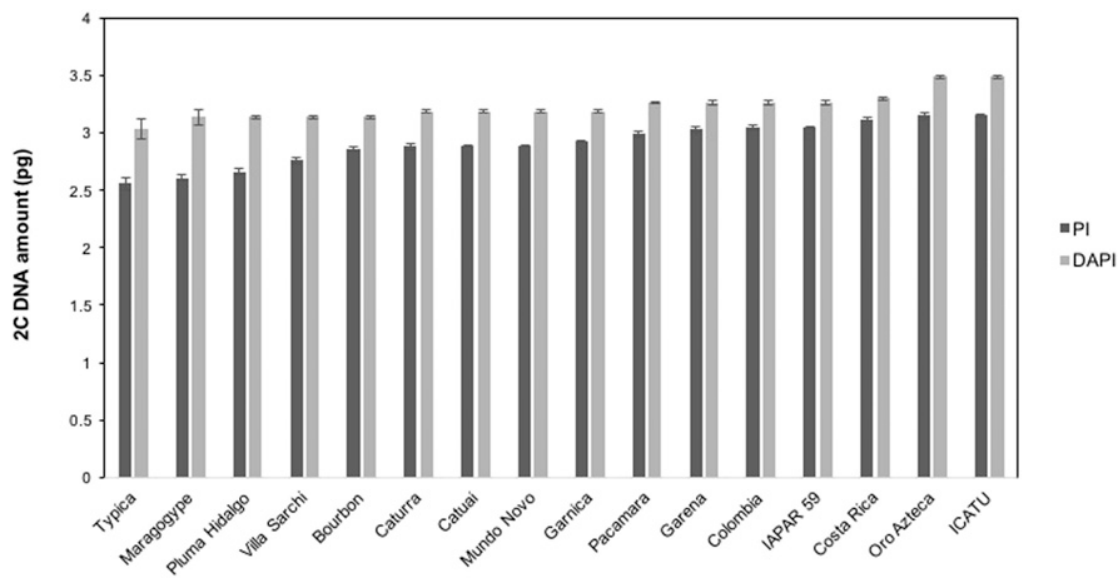

Fig. 3. DNA 2C-values experimentally measured of tested cultivars with two dyes. Genome size of all C. arabica cultivars arranged by ascending order when nuclei were stained with PI and when nuclei were stained with DAPI. PI = propidium iodide; DAPI = 4', 6' -diamino-2-phenylindole dihydrochloride hydrate.

'ICATU', cultivar generated between the hybrid 'Bourbon' $\times$ C. canephora and 'Caturra' (Fig. 4). These cultivars are highly

appreciated due to their partial resistance to the rust races affecting $C$. arabica trees around the world. However, currently there are no cultivars harboring all the resistance genes identified to date (Anthony et al., 2001; Diola et al., 2013); therefore, techniques that increase genetic diversity will be very important for the control or mitigation of coffee rust, among other diseases of this fundamental crop.

The first step in FCM analysis was to define the $2 \mathrm{C}$-values of the standards, a closer value (in this study, $2 \mathrm{C}=2.30 \pm 0.030 \mathrm{pg}$ ) to those reported by Arumuganathan and Earle (1991) $(2 \mathrm{C}=2.31 \mathrm{pg})$ and Vilhar et al. (2001) $(2 \mathrm{C}=2.34 \mathrm{pg})$ in soybean, which contains AT $\%=63.6 \%$ (Abreu et al., 2011; Barow and Meister 2002; Meister and Barow, 2007). Doležel and Greilhuber (2010) suggest that, to be useful as a primary standard, a plant must have, among others, similar, but not identical, genome size to the analyzed plant, and the G0/G1 peaks of the standard should not overlap to the peaks of the sample. In addition, the standard must be easy to use, genetically stable, nuclei must be obtained in enough amounts for analysis, and its genome size must be known with great precision as well as similar AT\%. Soybean has all these characteristics and is one of the eight best primary standards according to Praça-Fontes et al. (2011). Besides, considering the occurrence of pseudo variations and consequent inaccurate genome size estimations, it is desirable to use more than one standard. In this work $C$. canephora $(2 \mathrm{C}=1.29 \pm 0.051$ pg) also was employed as secondary standard (data shown in Supplemental Tables 1-3) considering its relatedness to C. arabica. The genome content of $C$. canephora has been reported ranged from 1.20 to $1.40 \mathrm{pg}$ (Cros et al., 1995; Noirot et al., 2003a, 2003b) with a $\mathrm{AT} \%=64.46$ (Clarindo et al., 2012).

Genome size determination tests depend on different factors, due to its indirect nature, influenced by the $\mathrm{GC} \%$, as well as the potential presence of compounds that fluoresce in the same wavelength, thus over or underestimating the experimental values. Considering that the genome of soybean and $C$. canephora is already known, the closest values to the actual estimate are those obtained with the method using PI. In Fig. 5, genome size values is shown using two standards, in which the estimates of the cultivars based on the comparison with the soybean genome, are greater. As a speculative note, it can be considered that the staining of the cultivars using two different standards could be similar, because they are of the same species. However, soybean, being a different tissue from another species, may have a greater affinity for the dye, associated with inherent properties at the time of sample processing. Despite this, the variation is consistent, which allows us to rely on the estimates obtained.

FCM parameters of $16 C$. arabica cultivars, such as G0/G1 nuclei peaks, nuclei count, and $\mathrm{CV}$ values are close to $5 \%$ (Table 1), were similar to the results obtained by Clarindo et al. (2013). In agreement with Doležel and Bartos (2005), CV lower than $5 \%$ are considered better for 


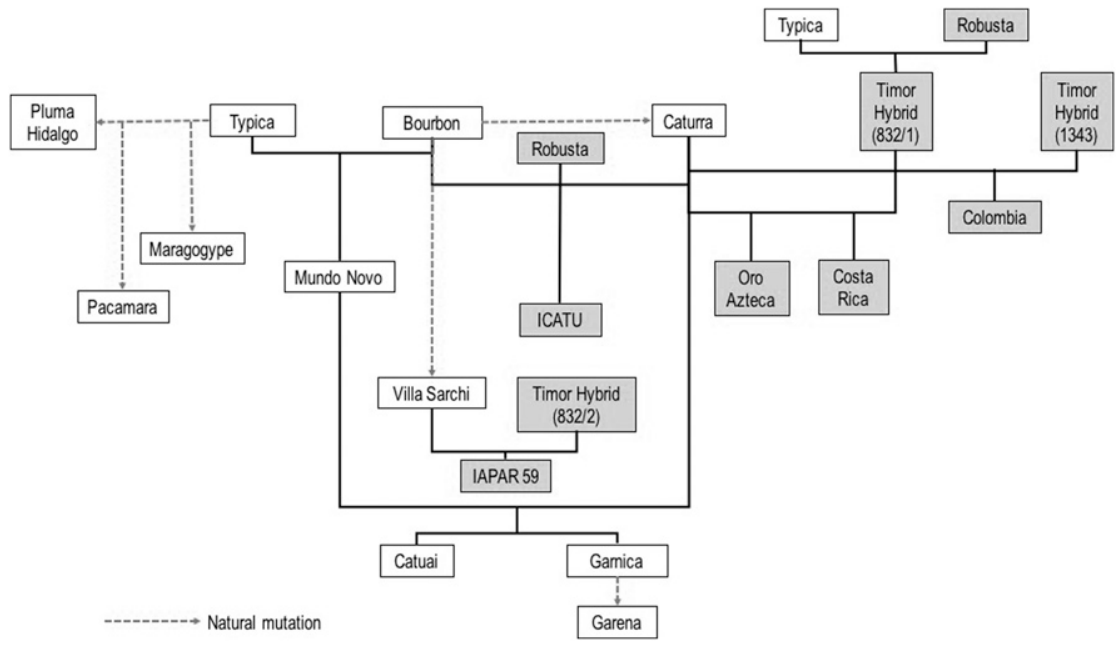

Fig. 4. Genealogy of the coffee cultivars analyzed in this study. Different lineages are distinguished in commercial cultivars giving rise to the extant cultivars: Pluma Hidalgo and Typica, Typica and Bourbon, Bourbon and Caturra, and Typica and Robusta. The cultivars indicated with a dashed arrow were obtained as natural mutations ('Pluma Hidalgo', 'Pacamara', 'Maragogype', 'Bourbon', 'Villa Sarchi', and 'Caturra'). The Bourbon and Typica cultivars generated 'Mundo Novo', which with 'Caturra' generated 'Catuai', 'Garnica', and 'Garena', whereas 'Villa Sarchi' and 'Timor' hybrid 832/ 2 generated 'IAPAR 59'. Another identified group resulted from the 'Typica' and 'Robusta' genetic cross, thus generating the 'Timor' hybrid 832/1, which with 'Caturra' produced 'Oro Azteca' and 'Costa Rica' cultivars. The 'Timor' hybrids $832 / 1$ and 1343 generated the commercial cultivar Colombia. Cultivars showing partial resistance to coffee rust are highlighted in shaded boxes. International code for Timor cultivars accessions are indicated in parenthesis.

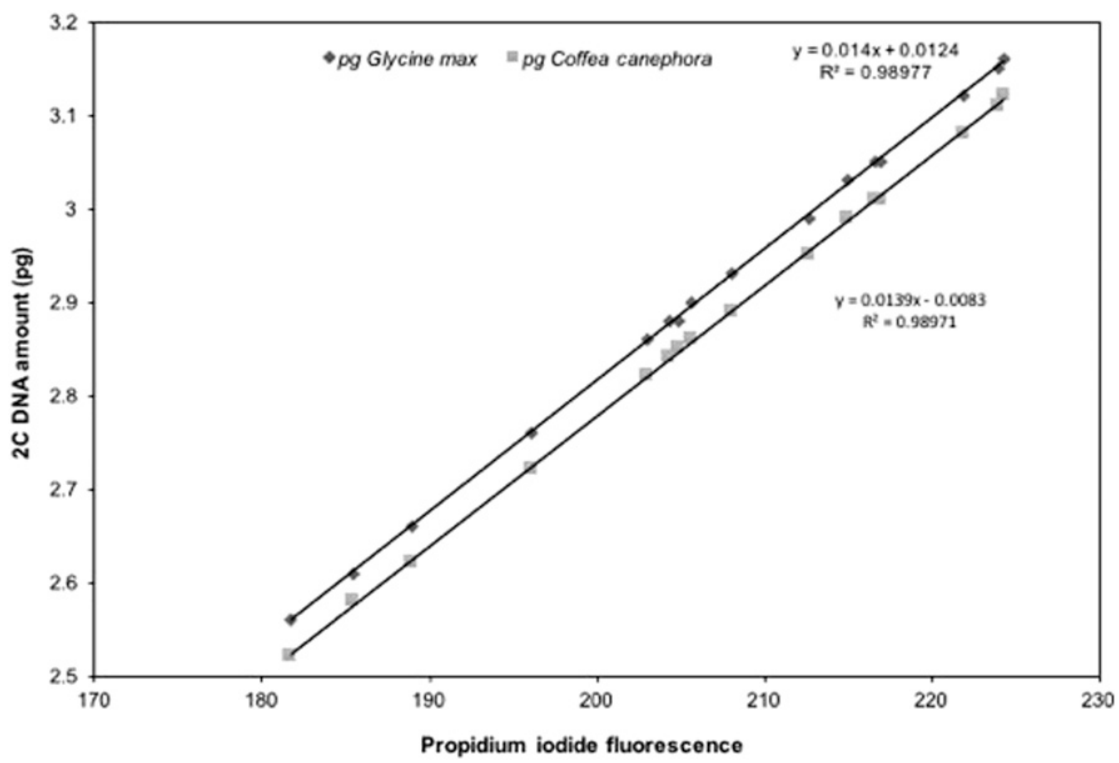

Fig. 5. Lineal comparison of DNA nuclear content among $C$. arabica cultivars using two different standards. Similar slope $\left(R^{2}=0.98\right)$ in all evaluated cultivars was found when nuclei was stained with propidium iodide.

FCM measurements. Clarindo et al. (2012) described that in some $C$. arabica cultivars it is very difficult to obtain $\mathrm{CV}$ values at the level recommended by Doležel and Bartos (2005). These complications are caused by the presence of autofluorescent and phenolic compounds in C. arabica leaves, causing interference with the accessibility of the dye to the DNA (Noirot et al., 2003b). In the present work, we carried out tests for the presence of inhibitors (Choudhury et al., 2014; Huang et al., 2013); a protocol was
C. canephora and C. arabica genome size estimations using fluorochromes PI and DAPI has been reported by Clarindo et al. (2012). Sisko et al. (2003) found a similar positive correlation $\left(R^{2}=0.82\right)$ between PI and DAPI values in members of the Cucurbita genus. Greater genome size values obtained with DAPI than PI has been reported in other plant species such as Magnolia, Narcissus, Cotoneaster, and Acer (Contreras and Shearer, 2018; Marques et al., 2011; Parris et al., 2010; Rothleutner et al., 2016). Noirot et al. (2002) and Doležel et al. (1992) found an overestimation of genome size values using DAPI. Different Factors such as differences in base composition between the standard and measured sample, as well as differences in binding properties of the fluorochromes, contributing to affect this overestimation when using base specific fluorochromes like DAPI. Nevertheless, it is a practical fluorochrome to calculate a relative genome size. In addition, it can supply a tool for estimating base composition when used in conjunction with an intercalating dye such as PI (Contreras and Shearer 2018).

Regarding base composition, Clarindo et al. (2013) has reported AT\% $=63.84$, in C. arabica cultivar Catuai vermelho. In this study, we found AT\% between $60.78 \%$ and $62.97 \%$. Whereas the GC\% obtained in this work (ranged from $37.03 \%$ to $39.22 \%$ ) is similar to reported by Clarindo et al. (2012), there is no general correlation between genome size and AT/GC ratio in higher plants. Similar AT/GC ratios within a plant family result from the general similarity of the DNA sequences within a family. The fluorescence of base-specific dyes is influenced by the nonrandom distribution of bases in the DNA molecule (Barow and Meister, 2002). Statistical analysis can help assess the extent of genome size variation among varieties of related species or cultivars. Indeed, LSD allows to determine with relative ease whether populations are truly different from the rest, more so when standard deviations and means are not useful parameters in this regard. This tool is particularly useful for the study of agronomically important traits. In the case of C. arabica it is important to determine the genetic variability between different cultivars (including genome size) since most of them are not biologically defined species, but rather the result of somatic mutations and artificial hybridization. This has generated plants with sexual incompatibility, a prolonged juvenile phase, high homozygosity, complex hybridization patterns, and low seed germination rate. Thus, FCM analysis applied to estimate total nuclear DNA content in C. arabica cultivars and its analysis by, LSD can help to identify those cultivars with higher possibilities of having sexual compatibility and therefore hybridization via conventional breeding. The LSD analysis shown here allowed us to distinguish variations of $0.133 \mathrm{pg}$ in nuclear DNA content. The cultivar with lower DNA content was 'Typica' with $2.56 \mathrm{pg}$, in which $0.133 \mathrm{pg}$ corresponds to $5 \%$ sensitivity, which is acceptable for a statistical 
test; however, among many cultivars, the detectable difference is lower than the statistical analysis allows. In contrast, even though some of these cultivars arose as the result of natural mutations and are thus related, cultivars that resulted from these mutations have a different DNA content relative to their progenitors (such is the case of 'Pacamara' and 'Maragogype'). Other cultivars have different genetic origin and yet possess similar DNA content, i.e., 'Pacamara' and 'Garena'. In general, cultivars resulting from spontaneous mutations have greater DNA content than cultivars from which they originated. This is the case of the Typica cultivar that gave rise to 'Maragogype', 'Pacamara', and 'Pluma Hidalgo'. A similar situation is found in the case of the Caturra cultivar with greater DNA content than its parent 'Bourbon'. The estimation of genome with PI using primary standard shows two groups, which are significant different $\left(\operatorname{LSD}_{0.05}=0.13356\right)$. The first represents Typica-related cultivars, with lower genome content ('Maragogype', 'Pluma Hidalgo', 'Villa Sarchi', 'Bourbon', 'Caturra', 'Catuai', and 'Mundo Novo'), whereas the second includes the introgressed cultivars Colombia, IAPAR 59, Costa Rica, Oro Azteca, and ICATU. Parallel estimations were obtained when DAPI was employed, genome size was estimated between 3.03 and $3.19 \mathrm{pg}$ for 'Typica'-related family and 3.27 to $3.50 \mathrm{pg}$ for introgressed family (Table 1). Different hybrids populations exhibit similar intraspecific variation, compared with the parental species (Baack et al., 2005; Marques et al., 2011). Intraspecific variation also has been reported in diploid Coffea species from Africa (Noirot et al., 2002), as well as from islands in the Indian Ocean (Razafinarivo et al., 2013). Also, divergence and genetic diversity has been found in different $C$. canephora genotypes (Dalcomo et al., 2015; Giles et al., 2018) It is known that variations in genome size is mainly affected by retrotransposons, structural rearrangements, deletions at the individual chromosomal level, and illegitimate recombination (Bennetzen et al., 2005; Grover and Wendel, 2010; Williams et al., 2002). Mechanisms underlying intraspecific and interspecific genome size variation in plants, particularly at the evolutionary level are not well understood; thus, more research is required in this regard. A second relevant aspect of our study is the genome size differences estimated with PI, where no significant differences $\left(\mathrm{LSD}_{0.05}=0.13356\right)$ were found between natural hybrids ('Garnica', 'Pacamara', 'Garena') and the synthetic hybrids ('Colombia', 'IAPAR 59', 'Costa Rica', 'Oro Azteca', and 'ICATU'). Marques et al. (2011) mentioned that one possible explanation for this pattern is that individuals studied from the natural hybrid populations represent late hybrid generations, which would have undergone substantial genome size changes as compared with F1s or are simply a mixture of hybrid genotypes, not necessarily from late hybrid generations.

In conclusion, FCM was used for the estimation of genome size and $\mathrm{GC} \%$ content in 16 C. arabica cultivars, which allowed the identification of different groups that agree with the previously grouping described, obtained through phylogenetic and amplified fragment length polymorphism analysis (Anthony et al., 2002; Giles et al., 2019; Machado et al., 2017; Steiger et al., 2002). This information could be helpful for $C$. arabica breeding programs, given the paucity of genome size studies with FCM in different important $C$. arabica cultivars (such as the group corresponding to the 'Bourbon' and 'Typica' genetic family hybrids and artificial crosses). Additionally, these results may be relevant for genomic analysis as well as for a better understanding of $C$. arabica evolutionary relationships, diversification, hybridization, and polyploidy.

\section{Literature Cited}

Abreu, I.S., C.R. Carvalho, C.R. Carvalho, G.M.A. Carvalho, and S.Y. Motoike. 2011. First karyotype, DNA C-value and AT/GC base composition of macaw palm (Acrocomia aculeata, Arecaceae) a promising plant for biodiesel production. Austral. J. Bot. 59:149-155.

Anthony, F., B. Bertrand, O. Quiros, A. Wilches, J. Bertraud, and A. Charrier. 2001. Genetic diversity of wild coffee (Coffea arabica L.) using molecular markers. Euphytica 118:53-65.

Anthony, F., M.C. Combes, C. Astorga, B. Bertrand, G. Graziosi, and P. Lashermes. 2002. The origin of cultivated Coffea Arabica L. cultivars revealed by AFLP and SSR markers. Theor. Appl. Genet. 104:894-900.

Arumuganathan, K. and E.D. Earle. 1991. Nuclear DNA content of some important plant species. Plant Mol. Biol. Rpt. 9:208-218.

Baack, E.J., K.D. Whitney, and L.H. Rieseberg. 2005. Hybridization and genome size evolution: Timing and magnitude of nuclear DNA content increases in Helianthus homoploid hybrid species. New Phytol. 167:623-630.

Barow, M. and A. Meister. 2002. Lack of correlation between AT frequency and genome size in higher plants and the effect of nonrandomness of base sequences on dye binding. Cytometry A 47:1-7.

Barre, P., M. Noirot, J. Louarn, C. Duperray, and S. Hamon. 1996. Reliable flow cytometric estimation of nuclear DNA content in coffee trees. Cytometry 24:32-38.

Bennett, M.D. and I.J. Leitch. 2005. Nuclear DNA amounts in angiosperms: Progress, problems, and prospects. Ann. Bot. 95:45-90.

Bennett, M.D. and I.J. Leitch. 2012. Plant DNA C-values database. (release 8.0, Dec. 2012). 11 Jan. 2018. <http://www.kew.org/cvalues/>.

Bennett, M.D., I.J. Leitch, H.J. Price, and J.S Johnston. 2003. Comparison with Caenorhabditis (100 Mb) and Drosophila (175 Mb) using flow cytometry show genome size in Arabdopsis to be $157 \mathrm{Mb}$ and thus $25 \%$ larger than the Arabdopsis Genome Initiative estimate of 125 Mb. Ann. Bot. 91:547-557.

Bennetzen, J., J. Ma, and K. Devos. 2005. Mechanisms of recent genome size variation in flowering plants. Ann. Bot. 95:127-132.

Carvalho, C.R. and W.R. Clarindo. 2011. Flow cytometric analysis using SYBR Green I for genome size estimation in coffee. Acta Histochem. 113:221-225.

Choudhury, R.R., S. Basak, A.M. Ramesh, and L. Rangan. 2014. Nuclear DNA content of Pongamia pinnata $\mathrm{L}$. and genome stability of in vitroregenerated plantlets. Protoplasma 251:703-709.
Clarindo, W.R. and C.R. Carvalho. 2009. Comparison of the Coffea canephora and C. arabica karyotype based on chromosomal DNA content. Plant Cell Rep. 28:73-81.

Clarindo, W.R., C.R. Carvalho, and M.A.C. Mendonça. 2012. Cytogenetic and flow cytometry data expand knowledge of genome evolution in three Coffea species. Plant Syst. Evol. 298:835-844.

Clarindo, W.R., C.R. Carvalho, E.T. Caixeta, and A.D. Koehler. 2013. Following the track of "Híbrido de Timor" origin by cytogenetic and flow cytometry approaches. Genet. Resources Crop Evol. 60:2253-2259.

Contreras, R.N. and K. Shearer. 2018. Genome size, ploidy, and base composition of wild and cultivated Acer. J. Amer. Soc. Hort. Sci. 143: 470-485.

Cros, J., M.C. Combes, N. Chabrillange, C. Duperray, A.M. Angles, and S. Hamon. 1995. Nuclear DNA content in the subgenus Coffea (Rubiaceae): Interand intra-specific variation in African species. Can. J. Bot. 73:14-20.

Cubry, P., P. Musoli, and H. Legnaté. 2008. Diversity in coffee assessed with SSR markers: Structure of the genus Coffea and perspectives for breeding. Genome 51:50-63.

Dalcomo, J. M., H.D. Vieira, A. Ferreira, W.L. Lima, R.G. Ferrão, A.F.A. Fonseca, and F.L. Partelli. 2015. Evaluation of genetic divergence among clones of conilon coffee after scheduled cycle pruning. Genet. Mol. Res. 4:15417-15426.

Diola, V., G.G. Brito, E.T. Caixeta, L.F.P. Pereira, and M.E. Loureiro. 2013. A new set of differentially expressed signaling genes is early expressed in coffee leaf rust race II incompatible interaction. Funct. Integr. Genomics 13:379-389.

Dodsworth, S., A.R. Leitch, and I.J. Leitch. 2015. Genome size diversity in angiosperms and its influence on gene space. Curr. Opin. Genet. Dev. 35:73-78.

Doležel, J. and J. Bartos. 2005. Plant DNA flow cytometry and estimation of nuclear genome size. Ann. Bot. 95:99-110.

Doležel, J. and J. Greilhuber. 2010. Nuclear genome size: Are we getting closer? Cytometry A 77:635-642.

Doležel, J., J. Greilhuber, S. Lucrettiii, A. Meister, M.A. Lysakt, and L. Nardiii. 1998. Plant Genome Size Estimation by Flow Cytometry Inter-laboratory Comparison. Ann. Bot. 82: $17-26$.

Doležel, J., J. Greilhuber, and J. Suda. 2007. Estimation of nuclear DNA content in plants using flow cytometry. Nat. Protoc. 2:22332244

Doležel, J., S. Sgorbati, and S. Lucretti. 1992. Comparison of three DNA fluorochromes for flow cytometric estimation of nuclear DNA content in plants. Physiol. Plant. 85:625-631.

Fontes, B.P.D. 2003. Citogenética, citometria de fluxo e citometria deimagem em Coffea spp. $\mathrm{PhD}$ Thesis, Univ. of Viçosa, Brazil.

Giles, J.A.D., A.D. Ferreira, F.L. Partelli, E.M. Aoyama, J.C. Ramalho, A. Ferreira, and A.R. Falqueto. 2019. Divergence and genetic parameters between Coffea sp. genotypes based in foliar morpho-anatomical traits. Scientia Hort. 245:231-236.

Giles, J.A.D., F.L. Partelli, A. Ferreira, J.P. Rodrigues, G. Oliosi, and F.H. Silva. 2018. Genetic diversity of promising 'conilon'coffee clones based on morpho-agronomic variables. An. Acad. Bras. Cienc. 90:2437-2446.

Godelle, B., D. Cartier, D. Marie, S.C. Brown, and S. Siljak-Yakovlev. 1993. Heterochromatin 
study demonstrating the non-linearity of fluorometry useful for calculating genomic base composition. Cytometry A 14:618-626.

Greilhuber, J. 2005. Intraspecific variation in genome size in angiosperms: Identifying its existence. Ann. Bot. 95:91-98.

Greilhuber, J. and J. Doležel. 2009. 2C or not 2C: A closer look at cell nuclei and their DNA content. Chromosoma 118:391-400.

Greilhuber, J., J. Doležel, M.A. Lysak, and M.D. Bennett. 2005. The origin, evolution and proposed stabilization of the terms 'genome size' and 'C-value' to describe nuclear DNA content. Ann. Bot. 86:859-909.

Grover, C.E. and J.F. Wendel. 2010. Recent insights into mechanisms of genome size change in plants. J. Bot. 2010:1-8.

Grover, C.E., Y. Yu, R.A. Wing, A.H. Paterson, and J.F. Wendel. 2008. A phylogenetic analysis of indel dynamic in the cotton genus. Mol. Biol. Evol. 7:1415-1418.

Herrera, J.C., M.C. Combes, H. Cortina, G. Alvarado, and P. Lashermes. 2002. Gene introgression into Coffea arabica by way of triploid hybrids ( $C$. arabica $\times$ C. canephora). Heredity. 89:488-494.

Huang, H., Y. Tong, Q.J. Zhang, and L.Z. Gao. 2013. Genome size variation among and within Camellia species by using flow cytometric analysis. PLoS One. 8:1-5.

International Coffee Organization. 3 Jan. 2018. $<$ http://www.ico.org/trade_statistics.asp $>$.

Lashermes, P., M.C. Combes, C. Ansaldi, E. Gichuru, and S. Noir. 2011. Analysis of alien introgression in coffee tree (Coffea arabica L.). Mol. Breed. 27:223-232.

Leong-Skornickova, J., O. Sída, V. Jarolímová, M. Sabu, T. Fér, P. Trávníček, and J. Suda. 2007. Chromosome numbers and genome size variation in Indian species of Curcuma (Zingiberaceae). Ann. Bot. 100:505-526.

Machado, C.M.S., N.S. Pimentel, A. Golynsk, A. Ferreira, H.D. Vieira, and F.L. Partelli. 2017. Genetic diversity among 16 genotypes of Coffea Arabica in the Brazilian cerrado. Genet. Mol. Res. 16:1-13.

Marques, I., G. Nieto-Feliner, M. A. MartinsLouçao, and J. Fuertes-Aguilar. 2011. Genome size and base composition variation in natural and experimental Narcissus (Amaryllidaceae) hybrids. Ann. Bot. 190:257-264.

Martins, M.Q., A.S. Fortunato, W.P. Rodrigues, F.L. Partelli, E. Campostrini, F.J.C. Lidon, F.M. DaMatta, J.C. Ramalho, and A.I. Ribeiro-Barros. 2017. Selection and validation of reference genes for accurate RT-qPCR data normalization in Coffea spp. under a climate changes context of interacting elevated [CO2] and temperature. Front. Plant Sci. 8:307.

Martins, M.Q., W.P. Rodrigues, A.S. Fortunato, A.E. Leitão, A.P. Rodrigues, I.P. Pais, L.D. Martins, M.J. Silva, F.H. Reboredo, F.L. Partelli, E. Campostrini, M.A. Tomaz, P. ScottiCampos, A.I. Ribeiro-Barros, F.J.C. Lidon, F.M. DaMatta, and J.C. Ramalho. 2016. Protective response mechanisms to heat stress in interaction with high [CO2] conditions in Coffea spp. Front. Plant Sci. 7:947.

Meister, A. and M. Barow. 2007. Nuclear DNA content measurement, p. 67-101. In: J. Doležel, J. Greilhuber, and J. Suda (eds.). Flow cytometry with plant cells: Analysis of genes, chromosomes and genomes. Wiley-VCH, Weinheim, Germany.

Mishra, M.K. and A. Slater. 2012. Recent advances in the genetic transformation of coffee. Biotechnol. Res. Intl. 2012:1-17.

Noirot, M., P. Barre, D. Christiphe, S. Hamon, and A. De Kochko. 2005. Investigation on the causes of stoichiometric error in genome size estimation using heat experiments: Consequences on data interpretation. Ann. Bot. 95: 111-118.

Noirot, M., P. Barre, C. Duperray, J. Louarn, and S. Hamon. 2003b. Effects of caffeine and chlorogenic acid on propidium iodide accessibility to DNA: Consequences on genome size evaluation in coffee tree. Ann. Bot. 92:259-264.

Noirot, M., P. Barre, J. Louarn, C. Duperray, and S. Hamon. 2000. Nucleus-cytosol interactions-a source of stoichiometric error in flow cytometric estimation of nuclear DNA content in plants. Ann. Bot. 86:309-316.

Noirot, M., P. Barre, J. Louarn, C. Duperray, and S. Hamon. 2002. Consequences of stoichiometric error on nuclear DNA content evaluation in Coffea liberica var. dewevrei using DAPI and propidium iodide. Ann. Bot. 89:385-389.

Noirot, M., V. Poncet, P. Barre, P. Hamon, S. Hamon, and A. De Kochko. 2003a. Genome size variations in diploid African Coffea species. Ann. Bot. 92:709-714.

The Observatory of Economic Complexity. 2018. 12 Oct. 2018 . <https://atlas.media.mit.edu/en/>.

Parris, J.K., T.G. Ranney, H.T. Knap, and W.V. Baird. 2010. Ploidy levels, relative genome sizes, and base pair composition in Magnolia. J. Amer. Soc. Hort. Sci. 135:533-547.

Praça-Fontes, M.M., C.R. Carvalho, W.R. Clarindo, and C.D. Cruz. 2011. Revisiting the DNA Cvalues of the genome size-standards used in plant flow cytometry to choose the "best primary standards." Plant Cell Rep. 30:1183-1191.

Price, H.J. 1988. DNA content variation among higher plants. Ann. Mo. Bot. Gard. 75:12481257.

Ramalho, J.C., F.M. DaMatta, A.P. Rodrigues, P. Scotti-Campos, I. Pais, P. Batista-Santos, and A.E. Leitão. 2014. Cold impact and acclimation response of Coffea spp. plants. Theor. Exp. Plant Physiol. 26:5-18.

Razafinarivo, N.J., R. Guyot, A.P. Davis, E. Couturon, S. Hamon, D. Crouzillat, and P. Hamon. 2013. Genetic structure and diversity of coffee (Coffea) across Africa and the Indian Ocean islands revealed using microsatellites. Ann. Bot. 111:229-248.

Razafinarivo, N.J., J.J. Rakotomalala, S.C. Brown, M. Bourge, S. Hamon, A. De Kochko, V. Poncet, C. Dubreuil-Tranchant, E. Couturon, R. Guyot, and P. Hamon. 2012. Geographical gradients in the genome size variation of wild coffee trees (Coffea) native to Africa and Indian Ocean islands. Tree Genet. Genomes 8:1345-1358.

Rodrigues, W. P., M. Q Martins, A.S. Fortunato, A.P. Rodrigues, J.N. Semedo, M.C. SimõesCosta, I.P. Pais, A.E. Leitão, F. Colwell, L. Goulao, C. Máguas, R. Maia, F.L. Partelli, E. Campostrini, P. Scotti-Campos, A.I. RibeiroBarros, F.C. Lidon, F.M. DaMatta, and J. Ramalho. 2016. Long-term elevated air $\left[\mathrm{CO}_{2}\right]$ strengthens photosynthetic functioning and mitigates the impact of supra-optimal temperatures in tropical Coffea arabica and C. canephora species. Glob. Change Biol. 22: 415-431.

Rothleutner, J.J., M.W. Friddle, and R.N. Contreras. 2016. Ploidy levels, relative genome sizes, and base pair composition in Cotoneaster. J. Amer. Soc. Hort. Sci. 141:457-466.

Sanglard, N.A., P.M. Amaral-Silva, M.C. Sattler, S.C. Cristina de Oliveira, A.C.P. Nunes, T.C.B. Soares, C.R. Carvalho, and W.R. Clarindo. 2017. From chromosome doubling to DNA sequence changes: Outcomes of an improved in vitro procedure developed for allotriploid "Híbrido de Timor" (Coffea arabica L. × Coffea canephora Pierre ex A. Froehner). Plant Cell Tissue Organ Cult. 131:223-231.

Sattler, M.C., C.R. Carvalho, and W.R. Clarindo. 2016. Regeneration of allotriploid Coffea plants from tissue culture: Resolving the propagation problems promoted by irregular meiosis. Cytologia 81:125-132.

Shapiro, H.M. 2005. Practical flow cytometry. 4th ed. Wiley, Hoboken, NJ.

Sisko, M., A. Ivancic, and B. Bohanec. 2003. Genome size analysis in the genus Cucurbita and its use for determination of interspecific hybrids obtained using embryo-rescue technique. Plant Sci. 165:663-669.

Steiger, D.L., C. Nagai, P.H. Moore, C.W. Morden, R.V. Osgood, and R. Ming. 2002. AFLP analysis of genetic diversity within and among Coffea Arabica cultivars. Theor. Appl. Genet. 105:209-215.

Tatum, T.C., L. Nunez, M.M. Kushad, and A.L. Rayburn. 2006. Genome size variation in pumpkin (Cucurbita sp.). Ann. Appl. Biol. 149:145-151.

Vilhar, B., J. Greilhuber, J.D. Koce, E.M. Temsch, and M. Dermastia. 2001. Plant genome size measurement with DNA image cytometry. Ann. Bot. 87:719-728.

Williams, R.R., S. Broad, D. Sheer, and J. Ragoussis. 2002. Subchromosomal positioning of the epidermal differentiation complex (EDC) in keratinocyte and lymphoblast interphase nuclei. Exp. Cell Res. 272:163-175.

World Coffee Research. 2018. 30 Sept. 2018. $<$ https://worldcoffeeresearch.org/>.

Yan, J., J. Zhang, K. Sun, D. Chang, S. Bai, Y. Shen, L. Huang, J. Zhang, Y. Zhang, and Y. Dong. 2016. Ploidy level and DNA content of Erianthus arundinaceus as determined by flow cytometry and the association with biological characteristics. PLoS One 11:1-14. 
Supplemental Table 1. Three independent repetitions of nuclear DNA amount of $C$. arabica cultivars using soybean $(2 \mathrm{C}=2.30 \mathrm{pg})$ as primary standard and $C$. canephora $(2 \mathrm{C}=1.29 \mathrm{pg})$ as secondary standard.

\begin{tabular}{|c|c|c|c|c|}
\hline Cultivars & & Replicatio & & Mean of fluorescence \\
\hline Soybean & 163.39 & 163.34 & 163.35 & $163.36 \pm 0.03$ \\
\hline Coffea canephora var. Robusta & 91.31 & 91.36 & 91.33 & $91.33 \pm 0.03$ \\
\hline Coffea arabica var. Typica & 181.54 & 181.86 & 181.70 & $181.70 \pm 0.16$ \\
\hline Coffea arabica var. Maragogype & 185.42 & 185.49 & 185.56 & $185.49 \pm 0.05$ \\
\hline Coffea arabica var. Pluma Hidalgo & 188.91 & 188.90 & 188.92 & $188.91 \pm 0.01$ \\
\hline Coffea arabica var. Villa Sarchí & 196.01 & 196.07 & 196.14 & $196.07 \pm 0.07$ \\
\hline Coffea arabica var. Bourbon & 202.97 & 202.96 & 202.98 & $202.97 \pm 0.01$ \\
\hline Coffea arabica var. Caturra & 204.41 & 204.37 & 204.33 & $204.37 \pm 0.04$ \\
\hline Coffea arabica var. Catuaí & 204.79 & 204.83 & 204.87 & $204.83 \pm 0.04$ \\
\hline Coffea arabica var. Mundo Novo & 205.66 & 205.70 & 205.64 & $205.67 \pm 0.03$ \\
\hline Coffea arabica var. Garnica & 208.09 & 208.10 & 208.13 & $208.11 \pm 0.02$ \\
\hline Coffea arabica var. Pacamara & 212.65 & 212.63 & 212.60 & $212.63 \pm 0.03$ \\
\hline Coffea arabica var. Garena & 214.91 & 214.95 & 214.98 & $214.95 \pm 0.04$ \\
\hline Coffea arabica var. Colombia & 216.60 & 216.65 & 216.62 & $216.62 \pm 0.03$ \\
\hline Coffea arabica var. IAPAR 59 & 216.83 & 216.99 & 216.91 & $216.91 \pm 0.08$ \\
\hline Coffea arabica var. Costa Rica & 221.76 & 221.99 & 221.96 & $221.90 \pm 0.13$ \\
\hline Coffea arabica var. Oro Azteca & 224.03 & 224.02 & 224.06 & $224.04 \pm 0.02$ \\
\hline Coffea arabica var. ICATU & 224.37 & 224.36 & 224.33 & $224.35 \pm 0.02$ \\
\hline
\end{tabular}

Supplemental Table 2. Nuclear DNA amount of C. arabica varieties stained with PI using C. canephora as standard.

AU12

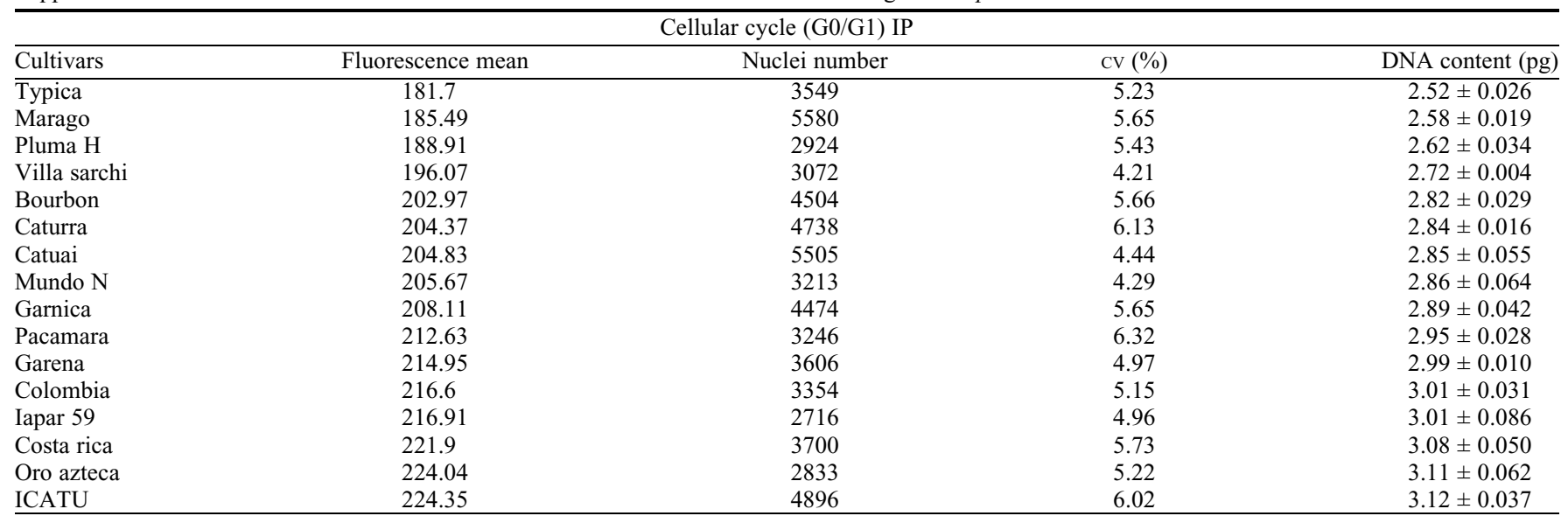

$\mathrm{PI}=$ propidium iodide.

Supplemental Table 3. Nuclear DNA amount of C. arabica cultivars stained with DAPI using soybean and C. canephora as standards.

\begin{tabular}{lccccc}
\hline \multicolumn{5}{c}{ Cellular cycle (G0/G1) DAPI } \\
\hline Cultivars & Fluorescence mean & Nuclei number & CV (\%) & Soybean DNA content (pg) & C. canephora DNA content (pg) \\
\hline Typica & 90.83 & 2173 & 5.85 & $3.03 \pm 0.042$ & $2.85 \pm 0.031$ \\
Marago & 93.79 & 6118 & 5.85 & $3.13 \pm 0.049$ & $2.94 \pm 0.012$ \\
Pluma H & 93.86 & 9193 & 5.55 & $3.13 \pm 0.050$ & $2.94 \pm 0.056$ \\
Villa sarchí & 94.19 & 7570 & 6.22 & $3.14 \pm 0.033$ & $2.95 \pm 0.073$ \\
Bourbon & 94.35 & 5910 & 5.88 & $3.15 \pm 0.027$ & $2.96 \pm 0.040$ \\
Catura & 95.49 & 7357 & 5.44 & $3.18 \pm 0.031$ & $3.99 \pm 0.066$ \\
Catuai & 95.61 & 9121 & 5.44 & $3.19 \pm 0.029$ & $3.00 \pm 0.25$ \\
Mundo N & 95.72 & 7229 & 5.48 & $3.19 \pm 0.032$ & $3.015 \pm 0.084$ \\
Garnica & 95.95 & 4834 & 5.65 & $3.20 \pm 0.027$ & $3.06 \pm 0.035$ \\
Pacamara & 97.50 & 6267 & 5.64 & $3.25 \pm 0.025$ & $3.06 \pm 0.041$ \\
Garena & 97.77 & 5950 & 5.55 & $3.26 \pm 0.026$ & $3.08 \pm 0.097$ \\
Colombia & 98.15 & 6908 & 4.87 & $3.27 \pm 0.019$ & $3.08 \pm 0.026$ \\
IAPAR 59 & 98.42 & 3628 & 5.09 & $3.28 \pm 0.022$ & $3.11 \pm 0.038$ \\
Costa rica & 99.12 & 8102 & 5.42 & $3.30 \pm 0.015$ & $3.27 \pm 0.075$ \\
Oro azteca & 104.26 & 5237 & 5.4 & $3.48 \pm 0.033$ & $3.45 \pm 0.043$ \\
ICATU & 104.96 & 6404 & 5.09 & $3.50 \pm 0.030$ & \\
\hline
\end{tabular}

DAPI $=4^{\prime}, 6^{\prime}$-diamino-2-phenylindole dihydrochloride hydrate. 